\title{
A Inserção dos Africanos na Zona da Mata - Minas Gerais, Século XIX
}

\author{
Jonis Freire ${ }^{1}$
}

\begin{abstract}
Resumo: O artigo aborda a inserção dos africanos em duas propriedades da Zona da Mata Mineira antes e após o fim do tráfico transatlântico de cativos em 1850. Percebe-se a importância deste mecanismo de reprodução da mão-de-obra para a manutenção/ampliação do contingente escravo. Detectamos que os escravos adquiridos por esses senhores eram, em sua maioria, advindos de uma determinada região do continente africano, e que estes africanos eram, majoritariamente, homens em idade produtiva (típicos de regiões de plantation), tendência que transparece mesmo após o fim do tráfico e em outras regiões da província mineira. A nosso ver são as tradições e memórias desses cativos que influenciaram a formação das comunidades escravas daquela região durante o século XIX.
\end{abstract}

Palavras-chave: África, tráfico transatlântico, demografia da escravidão, comunidade escrava, Minas Gerais.

The insertion of Africans in the Zona da Mata - Minas Gerais, century

Abstract: The article discusses the insertion of Africans in two properties of the Zona da Mata Mineira before and after the end of the transatlantic slave captives in 1850. Note the importance of this mechanism of reproduction of the labor force for the maintenance/expansion of the number of slaves. We have detected that slaves acquired by these owners were mostly coming from a particular region of Africa, and that these Africans were mostly men of productive age (typical of plantation areas), and this is reflected even after the end trafficking and other regions of the province of Minas Gerais. As we are the traditions and memories of those captives that influenced the formation of the slave communities of the region during the nineteenth century.

Keywords: Africa, transatlantic traffic, demography of slavery, the slave community, Minas Gerais.

O Brasil é notadamente reconhecido como tendo sido o locus para onde foi levado o maior contingente dos escravos transportados do continente africano. A historiografia sobre este tema desde muito tempo se debruça, dentre outros aspectos, sobre as possibilidades encontradas pelos proprietários brasileiros no que diz respeito à aquisição de sua mão-de-obra escrava, às rotas e ao volume do tráfico. ${ }^{2}$

Herbert Klein procurou sintetizar alguns dos eventos que levaram a América Portuguesa a se firmar como a maior absorvedora de mão-de-obra africana durante o século XIX. De acordo com Klein:

\begin{abstract}
Os portugueses permaneceram como os maiores traficantes durante a maior parte do século XIX em virtude de três fatores: $\mathrm{O}$ fim dos tráficos de escravos norteamericano e britânico em 1808, a destruição da frota escrava francesa durante a era da Revolução Francesa e a abolição formal da maior parte do tráfico europeu nas três primeiras décadas do novo século. A abolição da escravidão, em 1834, nas colônias inglesas e, em 1848, nas colônias francesas eliminou totalmente estas regiões como importadoras de escravos. ${ }^{3}$
\end{abstract}

\footnotetext{
${ }^{1}$ Doutor em História pela Unicamp; Professor do Programa de Pós-Graduação em História da Universidade Salgado de Oliveira (UNIVERSO/Niterói).

2 SLENES, Robert. Op. cit., 1976; KLEIN, Herbert. Op. cit. 1987; FLORENTINO, Manolo. Op. cit. 1997; RODRIGUES, Jaime. Op. cit., 2000.

${ }^{3}$ KLEIN, Herbert. Escravidão africana: América Latina e Caribe. São Paulo: Brasiliense, 1987, p. 169.
} 
Sobre esse grande número de cativos de origem africana e sua consequente importância cultural, cremos que os argumentos de Robert Slenes são bastante elucidativos. Segundo este pesquisador:

\begin{abstract}
Nas regiões de grande lavoura no Rio de Janeiro e em São Paulo, e nas áreas agropecuárias mais dinâmicas do Sul de Minas Gerais, a escravidão na primeira metade do século XIX era quase literalmente "africana". Recenseamentos da época indicam que cerca de $80 \%$ dos cativos adultos (acima de 15 anos) nessas regiões provinham da África. Além disso, os adultos "crioulos" (nascidos no Brasil) provavelmente eram, majoritariamente, filhos de africanos. Portanto, falar das esperanças e recordações dos cativos nesta parte do Brasil implica necessariamente em voltar a atenção para a herança cultural que os desterrados da África trouxeram consigo. ${ }^{4}$
\end{abstract}

O tráfico internacional de escravos provenientes da África, um dos responsáveis pelo aumento da mão-de-obra cativa, é uma das perspectivas analíticas sobre a reprodução dos escravos no Brasil. ${ }^{5}$ Outra vertente de análise sobre o crescimento da população escrava é a da reprodução natural dos cativos. Segundo alguns estudiosos, o aumento do contingente escravo por meio do nascimento poderia permitir uma possível manutenção e/ou ampliação da mãode-obra cativa. ${ }^{6}$

\footnotetext{
4 SLENES, Robert W. Na senzala uma flor: esperanças e recordações na formação da família escrava -Brasil Sudeste, século XIX. Rio de Janeiro: Nova Fronteira, 1999, p.142.

${ }^{5}$ Cf., entre outros, MOTTA, José Flávio e MARCONDES, Renato Leite. "O comércio de escravos no vale do Paraíba paulista: Guaratinguetá e Silveiras na década de 1870.” Estudos Econômicos. São Paulo: IPE/USP, 30(2): pp.267-299, 2000. SLENES, Robert W. The Brazilian Internal Slave Trade, 1850-1888: Regional economies, slave experience and the politics of a peculiar market. In: Walter Johnson. (Org.). Domestic Passages: Internal Slave Trades in the Americas, 1808-1888. New Haven: Yale University Press, 2005. SLENES, Robert W. The demography and economics of brazilian slavery: 1850-1888. Tese de Doutoramento. Stanford University, 1976. KLEIN, Herbert S. "A demografia do tráfico atlântico de escravos para o Brasil." Estudos Econômicos, São Paulo, v.17, n. 2, pág. 129149, maio/ago. 1987. FLORENTINO, Manolo. Em costas negras: uma história do tráfico de escravos entre a África e o Rio de Janeiro, século XVIII e XIX. São Paulo: Companhia das Letras, 1997. RODRIGUES, Jaime. O infame comércio: propostas e experiências no final do tráfico de africanos para o Brasil (1800-1850). Campinas: Editora da Unicamp/CECULT, 2000.

${ }^{6}$ PAIVA, Clotilde A. \& LIBBY, Douglas C. "Caminhos alternativos: escravidão e reprodução em Minas Gerais no século XIX.” Estudos Econômicos. São Paulo: IPE/USP, 25(2): 203-233, maio/ago., 1995. GUTIÈRREZ, Horacio. "Demografia escrava numa economia não-exportadora: Paraná, 1800-1830." Estudos Econômicos, São Paulo, v. 17, n. 2, p.297-314, maio-ago. 1987. SANTOS, Jonas Rafael dos. "Senhores e escravos: a estrutura da posse de escravos em Mogi das Cruzes no início do século XIX.” Estudos de História, Franca, SP, v.9, n.2, p.235253, 2002. BOTELHO, Tarcísio Rodrigues. Famílias e escravarias: demografia e família escrava no norte de Minas Gerais no século XIX. São Paulo: FFLCH/USP, 1994. (Dissertação de Mestrado). BOTELHO, Tarcísio Rodrigues. "Famílias e escravarias: demografia e família escrava no norte de Minas Gerais no século XIX." População e família, São Paulo, v.1, n.1, p. 211-234, jan./jun., 1988. BERGAD, Laird W. Escravidão e história econômica: demografia de Minas Gerais, 1720-1888. Bauru, SP: EDUSC, 2004. Algumas críticas sobre o trabalho de Bergad, feitas por Libby, podem ser vistas em uma resenha no American Historical Review, 107,1 (2002), 258-9. E também em LIBBY, Douglas Cole. Minas na mira dos Brasilianistas: reflexões sobre os trabalhos de Higgins e Bergad. In: BOTELHO, Tarcísio Rodrigues (Org.). História Quantitativa e Serial: um balanço. Belo Horizonte: ANPUH-MG, 2001. NOGUERÓL, Luiz Paulo Ferreira de. Economia escravista e preços de escravos em Minas Gerais: o caso de Sabará entre 1850 e 1887. Belo Horizonte: UFMG/CEDEPLAR, 1997. (Dissertação de Mestrado em Economia).
} 
Parece-nos inquestionável a afirmação de que o Brasil se utilizou, durante vários anos de sua colonização, do tráfico intercontinental com o intuito de adquirir mão-de-obra farta e relativamente barata devido ao grande fluxo de cativos. As estimativas sobre a quantidade de africanos trazidos para a América Portuguesa são muitas. Eduardo França Paiva, por exemplo, baseando-se em diversos autores, aponta a percentagem de 38\% de escravos africanos em direção ao Brasil entre os séculos XVI e XIX. Ao perdurar até o ano de 1850, o tráfico intercontinental garantiu o abastecimento da Colônia e depois do Império, até pelo menos esse ano, constituindo-se "em variável fundamental para a reprodução física da mão-de-obra cativa". ${ }^{7}$ Manolo Florentino em seu estudo sobre o tráfico de escravos, séculos XVIII e XIX, entre a África e o Rio de Janeiro (maior recebedor de escravos oriundos da África) afirmou que:

(...) se durante a primeira década do século XIX o porto do Rio continuou a deter quase metade das importações de africanos, a partir de então sua participação subiu vertiginosamente, variando entre $70 \%$ e $90 \%$ das importações de todo o país, índice que varia de acordo com o autor adotado como parâmetro para as estimativas das importações brasileiras. ${ }^{8}$

David Eltis, pesquisando o tráfico transatlântico de escravos para as Américas, percebeu que entre aqueles com nacionalidades conhecidas e que se aventuraram neste tipo de comércio, os portugueses foram os responsáveis pelos maiores volumes de mão-de-obra escrava. De acordo com os cálculos do pesquisador, entre os anos de 1519 e 1867, 5.074.900 africanos fizeram parte do comércio transatlântico de africanos, tendo os portugueses à frente dos negócios. Isto correspondeu a 45,9\% do total de escravos comercializados entre aqueles anos. Em segundo lugar vinham os ingleses com $28,1 \%$ e os franceses com 13,2\%. Segundo Eltis, durante este mesmo período, a maior parte dos cativos despachados para as Américas eram da região da West Central Africa - portos de Malembo, Loango, Cabinda, Ambriz, Benguela - 44,2\% (4.887,500 escravos). Seguidos pelos de Bight of Benin e Bight of Biafra, com respectivamente, $18,4 \%$ (2.034,600 escravos) e 13,7\% (1.517, 900 escravos). ${ }^{9}$

Com relação ao volume de cativos chegados em diversas regiões das Américas por meio do tráfico transatlântico, o Brasil se sobressaiu como o local para onde foram enviadas as

TEIXEIRA, Heloisa Maria. Reprodução e famílias escravas de Mariana (1850-1888). São Paulo: Universidade de São Paulo, 2001. (Dissertação de Mestrado em História Econômica).

${ }^{7}$ FRAGOSO, João \& FLORENTINO, Manolo, 1990, p.20-34, Apud: FLORENTINO, op. cit., 1997, p. 27.

${ }^{8}$ Ibidem, p. 66.

${ }^{9}$ ELTIS, David. The volume and structure of the transatlantic slave trade: a reassessment. William and Mary Quaterly, 3d Series, Volume 58, Number I, January 2001. Tabelas I e II. 
maiores levas de cativos africanos. Conforme os dados de Eltis, o Nordeste brasileiro, juntamente com Bahia e o Sudeste foram responsáveis por 40,6\% dos 9.599,000 africanos traficados para as Américas entre os séculos XVI e XIX. O Sudeste do Brasil foi a região que recebeu o maior número de cativos, tanto em números absolutos quanto em números relativos, foram 2.017.900 indivíduos escravizados, o que equivalia a 21,0\% do total de cativos. Foi, sobretudo, entre os anos de 1801-1850 que ocorreram os maiores desembarques de africanos no Sudeste Brasileiro, foram 1.145 .100 cativos - 56,7\% dos desembarcados nesta região. Em anos precedentes (1519-1800) as cifras chegaram a $869.300(43,1 \%)$ e em anos posteriores o número caiu vertiginosamente quando chegou, entre 1851-1867, a 0,2\%, o que correspondia a 3.600 africanos. $^{10}$

Minas Gerais é considerada pelos pesquisadores como a maior possuidora de escravos no século XIX. ${ }^{11}$ Cremos que o tráfico de escravos está entre os motivos que explicam o grande contingente de cativos na Província Mineira durante o século XIX, oriundos num primeiro momento do continente africano e depois do tráfico nacional interno. Claro está que as duas possibilidades, reprodução natural e tráfico, podem não ser excludentes, mas complementares. ${ }^{12}$

Conforme estimativas de Eduardo França Paiva, desde o século XVIII a capitania contava com um alto número de cativos. Segundo sua análise em testamentos e inventários, para as Comarcas do Rio das Mortes e Rio das Velhas, eram cerca de 2/3 de africanos e 1/3 de crioulos, sendo que estes últimos possuíam uma composição sexual mais equilibrada do que os africanos, àquela época com uma supremacia masculina. Com relação às procedências dos africanos, o autor indicou que a maioria era oriunda da Costa da Mina e de Angola. ${ }^{13}$

De acordo com o estudo sobre o tráfico atlântico de escravos realizado por Manolo Florentino, Minas Gerais se constituiu como um dos principais pontos de recebimento de cativos a partir do porto do Rio de Janeiro, nos primeiros anos do século XIX.

\footnotetext{
${ }^{10}$ Ibidem. Tabela III.

${ }^{11}$ Essa discussão pode ser vista em vários autores e ainda é norteada pelos trabalhos de: CANO, Wilson e LUNA, Francisco Vidal." A reprodução natural de escravos em Minas Gerais (século XIX): uma hipótese." Cadernos IFCH-UNICAMP. Campinas, SP, (10): 1-14, out. 1983. MARTINS, Roberto Borges. "Minas Gerais, século XIX: tráfico e apego a escravidão numa economia não-exportadora.” Estudos Econômicos, 13 (1): 181-209, jan./abr., 1983. SLENES, Robert. Os múltiplos de porcos e diamantes: a economia escrava de Minas gerais no século XIX. São Paulo: Estudos Econômicos, v.18, no 03, 1988.

${ }^{12}$ Conferir PAIVA, Clotilde A. \& LIBBY, Douglas C. Op. cit., 1995

13 PAIVA, Eduardo França. Escravidão e universo cultural na colônia: Minas Gerais, 1716-1789. Belo Horizonte: Editora da UFMG, 2001, p.118.
} 
Com relação à distribuição terrestre de africanos entre a segunda metade da década de 1820 e a primeira da seguinte, Minas Gerais, com sua economia voltada para o abastecimento (isto é, com a predominância de camponeses donos de pequenos plantéis de cativos), aparecia como pólo de absorção de $40 \%$ a $60 \%$ dos escravos que saíam do Rio de Janeiro. (...) O desempenho da economia mineira a transformava em um dos grandes pólos de demanda por africanos desembarcados no porto do Rio (...). ${ }^{14}$

Nesse aspecto chama atenção a região denominada de Zona da Mata ${ }^{15}$ e em especial o município de Juiz de Fora, que viria a ser detentor do maior contingente de escravos no correr do século XIX na Província de Minas Gerais. ${ }^{16}$ A análise das posses de escravos de duas famílias senhoriais, encabeçadas por Antonio Dias Tostes e pelo Comendador Francisco de Paula Lima, que consideramos representativas no tocante aos grandes proprietários da Mata Mineira, nos possibilita detectar quais as estratégias adotadas por esses senhores na composição de suas escravarias. ${ }^{17}$

Em uma região na qual desde o começo do século XIX o café vinha se estruturando como propagador do desenvolvimento da localidade, o que pode ser percebido dentre outros aspectos pelo crescimento demográfico daquela população, seu cultivo nas fazendas, sobretudo nas de maior porte, necessitava de mão-de-obra constante e abundante, e essa força de trabalho foi a escrava, principalmente a de origem africana. Acreditamos que esta maioria de africanos, seja no total dos escravos seja entre os jovens/adultos, deva ter conformado os padrões da comunidade escrava no Distrito de Santo Antonio do Paraibuna.

\footnotetext{
${ }^{14}$ FLORENTINO, op. cit., 1997, p. 38.

15 O crescimento demográfico da Mata Mineira foi bastante vertiginoso durante o século XIX. Muito provavelmente reflexo do desenvolvimento cafeeiro que impulsionava a formação de novas posses, bem como ampliava as já existentes. Em 1822 a região contava com 20.000 indivíduos, já em 1872 possuía 250.000 e em 1890, 430.000 habitantes. PIRES, Anderson José. Capital agrário, investimento e crise na cafeicultura de Juiz de Fora (1870-1930). Niterói, RJ: Universidade Federal Fluminense, 1993, p.33. (Dissertação de Mestrado em História).

16 A esse respeito entre outros ver ANDRADE, Rômulo Garcia de. Limites impostos pela escravidão a comunidade escrava e seus vinculos de parentesco: Zona da Mata de Minas Gerais, século XIX. São Paulo: USP, 1995. (Tese de Doutoramento). GUIMARÃES, Elione Silva. Múltiplos viveres de afrodescendentes na escravidão e no pós-emancipação: família, trabalho, terra e conflito (Juiz de Fora - MG, 1828-1928). São Paulo: Annablume; Juiz de Fora: Funalfa Edições, 2006b. LACERDA, Antonio Henrique Duarte. Os padrões de alforrias em um município cafeeiro em expansão: Juiz de Fora, Zona da Mata de Minas Gerais, 1844-1888. São Paulo: Fapeb; Annablume, 2006.

17 Essas famílias encabeçadas pelos ditos senhores são representativas no que diz respeito aos grandes proprietários da Zona da Mara Mineira que em geral possuíam grandes extensões de terra, produziam muito café tinham muitos cativos e grande prestígio social. Cf.: FREIRE, Jonis. Escravidão e família escrava na Zona da Mata Mineira oitocentista. Campinas, SP: Unicamp, 2009.
} 
Segundo Ângelo Alves Carrara, a Zona da Mata Mineira era, àquela época, uma área contígua ao Vale do Paraíba Fluminense, ${ }^{18}$ próxima ao porto do Rio de Janeiro, de onde eram escoadas as levas de escravos chegados do continente africano. A análise dessa região não só por sua importância econômica e demográfica, mas também pela geográfica, que sem dúvida contribuiu para suprir as posses de escravos encontradas naquela área, permite perceber de que forma o tráfico de cativos influiu na composição da escravaria da localidade, e porque não dizer da Província Mineira como um todo. Como bem salientaram Clotilde Paiva e Tarcísio Botelho:

\begin{abstract}
Sabe-se que nas décadas que antecederam a abolição do tráfico negreiro houve uma intensificação na entrada de escravos no Brasil, especialmente via porto do Rio de Janeiro, de onde vinham para Minas. É provável que, neste momento, as facilidades de importação de mão-de-obra cativa tenham levado os africanos a se espalharem por todos os pontos do território. No entanto, tanto o percentual de escravos na população total quanto a Razão de Sexos refletem diferenças regionais. No Sul, Mata e Mineradora as proporções estão quase sempre acima de 35\% e as Razões de Sexo próximas de dois homens por mulher. No Norte e Oeste as proporções são, na maioria dos casos, inferiores à $30 \%$ e há cerca de 1,2 homens para cada mulher. ${ }^{19}$
\end{abstract}

As altas taxas de razão de $\operatorname{sexo}^{20}$ encontradas na década de 30 dos oitocentos ainda se refletiram na segunda metade do século XIX mineiro e demonstram, segundo Paiva e Botelho, o movimento populacional anterior. Sobretudo em duas regiões que seriam o Sul, devido ao abastecimento para a Corte, e a Zona da Mata, que vinha iniciando sua expansão por meio do cultivo do café. Para eles: "Mesmo na segunda metade do século, estas duas áreas continuam mostrando algum sinal de desequilíbrio nas Razões de Sexo o que pode ser o resultado da importação (intra e/ou inter provincial) no crescimento da escravaria". ${ }^{21}$ De acordo com José Flavio Motta:

Se o predomínio crescente dos africanos patenteia a importância do tráfico externo de cativos, as cada vez maiores razões de masculinidade entre os escravos oriundos da África - sempre mais elevadas que as concernentes aos cativos nascido no Brasil - atestam a preferência dada à importação de indivíduos do sexo masculino. ${ }^{22}$

\footnotetext{
${ }^{18}$ CARrARA, Angelo Alves. A Zona da Mata de Minas Gerais: diversidade econômica e continuísmo (1839-1909). Niterói, RJ: Universidade Federal Fluminense, 1993. (Dissertação de Mestrado em História).

${ }_{19}$ PAIVA, Clotilde Andrade \& BOTELHO, Tarcísio Rodrigues. População e espaço no século XIX mineiro: algumas evidências de dinâmicas diferenciadas. In: Anais do VII Seminário Sobre a Economia Mineira. Belo Horizonte: CEDEPLAR/UFMG, 1995, p. 102.

${ }^{20}$ A razão de sexo é definida como o número de homens para cada grupo de 100 mulheres.

${ }^{21}$ Ibidem, p. 102.

22 MOTTA, José Flavio. Corpos escravos, vontades livres: posse de cativos e família escrava em Bananal (1801-1829). São Paulo: FAPESP: Annablume, 1999, p. 140.
} 
Os escravos pertencentes àquelas duas famílias, bem como os cativos de outros senhores escravistas, no Brasil Colonial e Imperial, foram a base de sua força de trabalho. Por meio deles se erigiram engenhos, fazendas de café, cidades, enfim, tudo que dependia de mãode-obra teve nesses indivíduos a fonte de trabalho. A rotina era extenuante tanto nas fazendas de café como em outras atividades. Sandra Graham sintetizou muito bem o panorama do mundo do trabalho desses escravizados:

\begin{abstract}
A maioria dos escravos trabalhava grande parte do tempo no café, mas alguns também plantavam milho, feijão e arroz e criavam gado. Escravos artesãos carpinteiros, ferreiros, pedreiros - construíam as casas, estradas e pontes de uma fazenda. Escravas domésticas cozinhavam, limpavam, lavavam e passavam roupas, carregavam água, esvaziavam os restos de cozinha e dejetos noturnos e entregavam recados. Uma escrava com leite de sua própria gravidez podia amamentar o bebê de sua senhora ou, como "ama-seca", cuidar dos filhos mais velhos dela. As crianças escravas tinham suas tarefas próprias: separar café, cuidar de cabras, descascar feijões, regar jardins ou cuidar dos menores. O número e a variedade de escravos qualificados dependiam do tamanho e da prosperidade da fazenda, da diversidade de sua produção e dos confortos que a família quisesse ter. ${ }^{23}$
\end{abstract}

Cabe agora visualizar um pouco mais de perto as posses das duas famílias alvo de nosso estudo. Um perfil desses cativos pode ser vislumbrado por meio do estudo das Listas Nominativas de Habitantes e dos Inventários post-morten. Vamos começar com a propriedade do capitão Antonio Dias Tostes, então com 55 anos de idade, e de longe o maior possuidor de cativos daquela localidade, de acordo com as Listas Nominativas de 1831. A maioria esmagadora de seus escravos foi descrita como africano/africana (126), e representava o maior número dos cativos existentes naquele fogo. Em seguida vinham os crioulos, num total de 19. Havia ainda 02 escravos pardos. Esses números absolutos demonstram a grande supremacia de homens e mulheres africanos em relação aos crioulos e pardos. Nessa propriedade havia uma maioria de cativos do sexo masculino, tanto entre africanos quanto entre crioulos, $73,0 \% \mathrm{e}$ $57,9 \%$, respectivamente. No entanto, é preciso ressaltar que os africanos eram quase três vezes mais do que suas parceiras de mesma origem. As cativas africanas (27,0\%), embora possuíssem um percentual menor do que as crioulas (42,1\%) eram em números absolutos mais representativas do que estas últimas. Esse fogo contava ainda com duas cativas designadas como pardas, que representavam a totalidade dos descritos como pardos (Tabela I).

\footnotetext{
${ }_{23}$ GRAHAM, Sandra Lauderdale. Caetana diz não: histórias de mulheres da sociedade escravista brasileira. São Paulo: Companhia das Letras, 2005, p. 42-43.
} 
Tabela I

Sexo e origem dos cativos de Antonio Dias Tostes, 1831*

\begin{tabular}{ccccccccc}
\hline $\begin{array}{c}\text { Origem } \\
\text { Sexo }\end{array}$ & Africano & $\mathbf{\%}$ & Crioulo & $\mathbf{\%}$ & Pardo & $\mathbf{\%}$ & Total & $\mathbf{\%}$ \\
\hline Masculino & 92 & 73,0 & 11 & 57,9 & - & - & 104 & 70,8 \\
Feminino & 34 & 27,0 & 08 & 42,1 & 02 & 100 & 43 & 29,2 \\
Total & $\mathbf{1 2 6}$ & $\mathbf{1 0 0}$ & $\mathbf{1 9}$ & $\mathbf{1 0 0}$ & $\mathbf{0 2}$ & $\mathbf{1 0 0}$ & $\mathbf{1 4 7}$ & $\mathbf{1 0 0 , 0}$ \\
\hline
\end{tabular}

Fonte: Mapas de população. Distrito de Santo Antonio do Juiz de Fora, Termo da Nobre e Muito Leal Vila de Barbacena, 1831. Arquivo Público Mineiro (doravante APM), Caixa 09; Documento 04.

De acordo com os passaportes e despachos emitidos na primeira metade do oitocentos pela Intendência de Polícia da Corte, Tostes levou para Minas Gerais 96 escravos. ${ }^{24}$ Em 24 de janeiro de 1829, comprou 22 cativos; no ano de 1830, foram outras três remessas, duas em janeiro e uma em abril, respectivamente, 20, 20 e 34 cativos, todos escravos novos conforme consta nas fontes. ${ }^{25}$ Sem dúvida, a família Tostes utilizou como estratégia de manutenção e/ou ampliação de suas posses em escravos o tráfico atlântico de escravos, por meio da compra na Corte; constituindo-se, conforme demonstrou Fabio W. Pinheiro, como uma das famílias da Mata Mineira que mais se utilizou deste tipo de reposição da mão-de-obra cativa. Ainda segundo este pesquisador:

\begin{abstract}
(...) Minas Gerais entre 1809 e 1830 foi o principal destino dos escravos, onde 40\% das almas despachados do Rio de Janeiro se dirigiram para este território, enquanto na província fluminense este índice foi de 36\%. Mais do que isso, verificamos também que dos escravos remetidos $97,8 \%$ eram africanos novos, se mostrando, assim, como um precioso indício da forte vinculação entre o tráfico Atlântico e a economia mineira. ${ }^{26}$
\end{abstract}

No ano de 1837 ocorreu a partilha dos bens da primeira esposa de Antonio Dias Tostes, Dona Anna Maria do Sacramento. Quanto à origem dos cativos, esta fonte demonstra que a grande maioria da escravaria dessa família continuava a ser composta por africanos, 108, os crioulos eram 33. Mesmo entre aqueles dos quais não foi possível conhecer a origem, os homens suplantam as mulheres, sendo 28 homens, 63,6\% e 16 mulheres, 36,4\% (Tabela II).

\footnotetext{
${ }^{24}$ Para um conhecimento a respeito desta documentação, bem como das possibilidades e "armadilhas" oriundas destas fontes, conferir: FRAGOSO, João Luis \& FERREIRA, Roberto Guedes. Alegrias e Artimanhas de uma fonte seriada, despacho de escravos e passaportes da Intendência de Polícia da Corte, 1819-1833. Seminário de História Quantitativa e serial no Brasil: um balanço. Ouro Preto, MG: ANPUH-MG, 2001.

${ }_{25}$ Respectivamente, Códice 421, v.21, p.255v; Códice 424, v.04, p. 27; Códice 424, v.04, p. 28; Códice 424, v.04, p. 114. Arquivo Nacional. (disponível no bando de dados do IPEA, CD-ROM).

${ }^{26}$ PINHEIRO, Fabio Wilson Amaral. O tráfico atlântico de escravos na formação dos plantéis mineiros, Zona da Mata (c.1809 - c.1830). Rio de Janeiro: Universidade Federal do Rio de Janeiro, 2007, p. 148-149. (Dissertação de Mestrado em História).
} 
Os crioulos e crioulas que se equilibravam no ano do recenseamento (1831), tinham agora (1837) uma supremacia dos homens, respectivamente, 66,7\% e 33,3\%.

Tabela - II

Sexo e origem dos cativos de D. Anna Maria do Sacramento, 1837

\begin{tabular}{ccccccccc}
\hline $\begin{array}{c}\text { Origem } \\
\text { Sexo }\end{array}$ & Africano & $\mathbf{\%}$ & Crioulo & $\mathbf{\%}$ & $\begin{array}{c}\text { Não } \\
\text { consta }\end{array}$ & $\mathbf{\%}$ & Total & \% \\
\hline Masculino & 81 & 75,0 & 22 & 66,7 & 28 & 63,6 & 131 & 71,0 \\
Feminino & 27 & 25,0 & 11 & 33,3 & 16 & 36,4 & 54 & 29,0 \\
Total & $\mathbf{1 0 8}$ & $\mathbf{1 0 0}$ & $\mathbf{3 3}$ & $\mathbf{1 0 0}$ & $\mathbf{4 4}$ & $\mathbf{1 0 0}$ & $\mathbf{1 8 5}$ & $\mathbf{1 0 0 , 0}$ \\
\hline
\end{tabular}

Fonte: Partilha dos bens de D. Anna Maria do Sacramento, 1837. Arquivo Histórico de Juiz de Fora (doravante AHJF).

Ao contrastarmos os dados das duas tabelas acima, verificamos uma pequena diminuição no número de africanos e um aumento no número de crioulos no decorrer daqueles seis anos. O número de cativos, onde não foi possível saber sobre sua procedência aumentou, entretanto, mesmo que fossem todos crioulos, o que não deve ser o caso, não conseguiriam suplantar os cativos provenientes da África.

Com relação ao sexo dos cativos, a propriedade dos Dias Tostes, possuía uma maioria de homens e africanos, típicos de uma propriedade de plantation, com razões de sexo bastante elevadas. Em 1831, computamos uma razão de 270,6 entre os africanos e 137,5 para os crioulos.

Perfil semelhante encontramos no ano de 1837, embora tenham diminuído o seu percentual, os africanos continuaram possuindo a supremacia nessa propriedade. Àquela época, as razões de sexo de africanos e crioulos eram, respectivamente, 300 e 200. Havia ainda os cativos sem origem conhecida, mas mesmo dentre estes a diferença era elevada, perfazendo 175 homens para cada grupo de cem mulheres.

A Tabela III nos permite tecer algumas considerações a respeito da faixa etária na qual se situavam esses cativos. Na faixa de 1-14 anos encontravam-se 35 cativos, vinte e três escravos africanos, $65,7 \%$; oito crioulos, $28,6 \%$ e as duas pardas, $5,7 \%$. Na segunda faixa etária (15 - 40 anos), composta pelo maior número dos cativos de Antonio Dias Tostes àquela época (105), estavam inclusos 99 africanos, 94,3\%, e seis crioulos 5,7\%. Finalmente a última (41 + anos), e a que contempla o menor número de cativos (07), possuía quatro africanos, $57,1 \% \mathrm{e}$ três crioulos, $42,9 \%$. 


\section{Tabela III}

Sexo e faixa etária dos cativos do Capitão Antonio Dias Tostes, 1831

\begin{tabular}{ccccccccc}
\hline $\begin{array}{c}\text { Faixa } \\
\text { etária } \\
\text { Sexo }\end{array}$ & $\begin{array}{c}\mathbf{1 - 1 4} \\
\text { (crianças) }\end{array}$ & $\mathbf{\%}$ & $\begin{array}{c}\mathbf{1 5 - 4 0} \\
\text { (jovens/adultos) }\end{array}$ & $\mathbf{\%}$ & $\begin{array}{c}\mathbf{4 1 +} \\
\text { (idosos) }\end{array}$ & $\mathbf{\%}$ & Total & \% \\
\hline Masculino & 21 & 60,0 & 77 & 73,3 & 05 & 71,4 & 103 & 70,1 \\
Feminino & 14 & 40,0 & 28 & 26,7 & 02 & 28,6 & 44 & 29,9 \\
Total & $\mathbf{3 5}$ & $\mathbf{1 0 0}$ & $\mathbf{1 0 5}$ & $\mathbf{1 0 0}$ & $\mathbf{0 7}$ & $\mathbf{1 0 0}$ & $\mathbf{1 4 7}$ & $\mathbf{1 0 0 , 0}$
\end{tabular}

Fonte: Mapas de população. Distrito de Santo Antonio do Juiz de Fora, Termo da Nobre e Muito Leal Vila de Barbacena, 1831. APM. Caixa 09; Documento 04.

Se subtrairmos os cativos na faixa de 1-14 anos do total de escravos encontrados na posse do Capitão Antonio Dias Tostes em 1831, encontramos um total de 103 africanos e 09 crioulos, dentro das duas outras faixas etárias expostas na tabela acima, ou seja, havia um percentual de $91,9 \%$ de africanos e $8,1 \%$ de crioulos. Fica claro, então, que o maior proprietário de escravos do Distrito de Santo Antonio do Juiz de Fora possuía uma posse majoritariamente composta de africanos em idade produtiva. ${ }^{27}$

Na partilha dos bens de Dona Anna Maria do Sacramento, ocorrida no ano de 1837, temos a oportunidade de avaliar a posse de escravos deste senhor (Tabela IV). Houve um aumento do número de cativos, que totalizavam 185 escravos. Portanto, durante este intervalo de tempo a posse de cativos desta família aumentou 25,9\%, em relação aos listados em 1831, agregando 38 escravos aquela comunidade.

Tabela IV

Sexo e faixa etária dos cativos de D. Anna Maria do Sacramento, 1837

\begin{tabular}{ccccccccccccc}
\hline $\begin{array}{c}\text { Faixa } \\
\text { etária } \\
\text { Sexo }\end{array}$ & $\begin{array}{c}\text { Recém } \\
\text { nascido* }\end{array}$ & $\mathbf{\%}$ & $\begin{array}{c}\mathbf{1 - 1 4} \\
\text { (crianças) }\end{array}$ & $\begin{array}{c}\mathbf{\%} \\
\text { (jovens/ } \\
\text { adultos) }\end{array}$ & $\begin{array}{c}\mathbf{4 1 +} \\
\text { (idosos) }\end{array}$ & $\begin{array}{c}\text { Não } \\
\text { consta }\end{array}$ & $\mathbf{\%}$ & Total & $\mathbf{\%}$ \\
\hline Masculino & 09 & 64,3 & 17 & 53,1 & 89 & 75,4 & 06 & 85,7 & 10 & 71,4 & 131 & 70,8 \\
Feminino & 05 & 35,7 & 15 & 46,9 & 29 & 24,6 & 01 & 14,3 & 04 & 28,6 & 54 & 29,2 \\
Total & $\mathbf{1 4}$ & $\mathbf{1 0 0}$ & $\mathbf{3 2}$ & $\mathbf{1 0 0}$ & $\mathbf{1 1 8}$ & $\mathbf{1 0 0}$ & $\mathbf{0 7}$ & $\mathbf{1 0 0}$ & $\mathbf{1 4}$ & $\mathbf{1 0 0}$ & $\mathbf{1 8 5}$ & $\mathbf{1 0 0}$ \\
\hline
\end{tabular}

Fonte: Partilha dos bens de D. Anna Maria do Sacramento, 1837. AHJF. * Crianças com menos de um ano de idade.

\footnotetext{
${ }^{27}$ Stanley Stein, em estudo sobre o Vale do Paraíba, com referência especial ao município de Vassouras, apontou os cativos entre 15 e 40 anos como sendo os "escravos em idade de trabalho eficiente. (...) segmento crucial da mão-de-obra das fazendas, (...)”. STEIN, op.cit., 1961, p. 93.
} 
Ainda de acordo com a partilha feita em 1837, nos foi possível saber a origem dos cativos. Encontramos a maioria dos africanos na faixa atribuída aos jovens, perfazendo 82 indivíduos, 69,5\%; seguidos por 02 crioulos, 1,7\%; para os outros 33 cativos não sabemos a origem, 28,8\%. Na faixa concernente às crianças existiu certo equilíbrio entre africanos e crioulos, respectivamente, quatorze $(43,8 \%)$ e quinze $(46,9 \%)$ havia ainda três crianças que não pudemos conhecer a origem (9,4\%). Existiam 14 recém-nascidos, treze deles de origem crioula $(92,9 \%)$, um não conhecemos a origem, entretanto, acreditamos que pela idade é muito provável que tenham sido crioulo. Embora não se saiba a taxa de mortalidade daquela população, parece que houve entre a lista de 1831 e a partilha em 1837 um crescimento vegetativo natural ${ }^{28}$ importante entre os cativos pertencentes aos Dias Tostes. Para outros 14 escravos não foi possível se conhecer a idade, o que nos impossibilitou determinar a que faixas pertenceram, oito africanos, dois crioulos e outros quatro sem origem descrita.

É fato que na primeira metade do século XIX o aumento do número dos cativos se deu por meio da mão-de-obra proveniente do tráfico atlântico. Nesse aspecto o conhecimento da procedência dos cativos africanos é um aspecto muito interessante, pois possibilita uma aproximação das regiões das quais vieram aqueles indivíduos. Entretanto, é preciso ressaltar que tais procedências podem dizer respeito apenas ao porto de onde foram embarcados, não correspondendo de imediato ao seu grupo de convívio.

Segundo os estudos realizados por Mary Karasch, os escravos africanos enviados para Minas Gerais, em 1831/1832, eram oriundos primeiramente do Centro-Oeste Africano, 40,6\%; África Oriental, 38,4\%; África Ocidental, 7,5\% e os escravos novos de origem desconhecida eram 13,5\%. A mesma autora atentou para a importância do comércio feito por meio dos traficantes mineiros: "Quem não tinha esse tipo de gente [escravos novos] comprava muitas vezes escravos de traficantes mineiros que os levavam para Minas Gerais". ${ }^{29}$

Diferente da relação de habitantes de 1831 que não descrevia as procedências dos cativos africanos, a partilha ocorrida em 1837 nos possibilitou conhecer um pouco mais sobre essa variável, pois designava a procedência dos africanos (Tabela V).

\footnotetext{
${ }^{28}$ Definido como a diferença positiva entre nascimentos e mortes

${ }^{29}$ KARASCH, Mary C. A vida dos escravos no Rio de Janeiro (1808-1850). São Paulo: Companhia das Letras, 2000, p. 96-97.
} 
Tabela V

Procedência dos cativos de Anna Maria do Sacramento, 1837

\begin{tabular}{cccc}
\hline Origem africana & Procedência & o de cativos & \% \\
\hline \multirow{2}{*}{ África Central ou Centro- } & Congo & 34 & 31,0 \\
Oeste Africano & Cabinda & 31 & 28,2 \\
& Monjolo & 07 & 6,3 \\
& Muange & 01 & 0,9 \\
\hline \multirow{2}{*}{ Angola } & Benguela & 17 & 15,5 \\
& Cassange & 08 & 7,3 \\
& Rebolo & 05 & 4,5 \\
\hline África Ocidental & Angola & 02 & 1,8 \\
\hline África Oriental & Mina & 01 & 0,9 \\
\hline Brasil & Moçambique & 03 & 2,7 \\
\hline - & Rio de Janeiro & 01 & 0,9 \\
\hline
\end{tabular}

Fonte: Partilha dos bens de D. Anna Maria do Sacramento, 1837. AHJF

Utilizando as classificações de Mary Karasch sobre as origens africanas dos cativos oriundos do tráfico para o Rio de Janeiro, encontramos na posse de Dona Anna Maria do Sacramento, no ano de 1837, dentre aqueles com procedência conhecida, uma maioria de cativos provenientes da "África Central ou Centro-Oeste Africano", formada pelas regiões do Congo Norte (66,4\%) e Angola (29,1\%), perfazendo no total 95,5\%. Eram 73 cativos procedentes da região do Congo Norte, compostos por 34 Congos (31,0\%), 31 Cabindas $(28,2 \%)$ e sete Monjolo (6,3\%); também do Centro-Oeste africano havia um Muange (0,9\%), que Karasch caracterizou como de região incerta. Da região de "Angola" eram 32 cativos, sendo de Angola Meridional 17 Benguela (15,5\%); os outros 14 eram do Norte de Angola oito Cassange (7,3\%), cinco Rebolo (4,5\%) e dois Angola (1,8\%). Da “África Oriental” temos três escravos de Moçambique, 2,7\%. Existia um cativo da "África Ocidental”, 0,9\%, de procedência Mina. ${ }^{30}$ Havia ainda 73 cativos sem esta variável mencionada.

Padrão semelhante foi encontrado por Fabio Pinheiro, que constatou, por meio da análise de inventários post-mortem, a hegemonia da África Central Atlântica enquanto principal área de procedência dos cativos levados a partir do Rio de Janeiro para a Zona da Mata Mineira, entre os anos de 1809 e 1830. Foram 93,8\% de cativos oriundos desta região, com

${ }^{30}$ Ibidem. 
ênfase para Angola, Congo e Benguela. Logo a seguir vinham os cativos da África Oriental (Moçambique), com 3,6\%, seguidos pelos da África Ocidental com cerca de 2,6\%. Buscando enriquecer seu conhecimento sobre este aspecto, o pesquisador utilizou os registros alfandegários para vislumbrar as procedências dos cativos despachados da Província carioca rumo à Província Mineira.

Por meio do cruzamento entre as principais áreas de origem dos africanos traficados a partir da praça mercantil carioca para a Província de Minas, Pinheiro pôde "perceber a possibilidade de uma coincidência entre a tendência das regiões de origem dos cativos do tráfico para Minas Gerais e os residentes na mata mineira". Naquele mesmo período (18091830), para os escravos onde foi possível se saber essa variável, 70,2\% eram da África Central Atlântica. Os da África Oriental perfizeram 21,6\%, enquanto que os cativos da África Ocidental foram $8,2 \%$. Interessante notar que quando este período é recortado entre os anos de 1809-1819 e 1820-1830, notou-se sempre, em termos percentuais, uma diminuição entre os cativos da África Central Atlântica e da África Ocidental e um aumento dos escravizados da África Oriental, entre aqueles traficados para Minas Gerais. ${ }^{31}$

Esse mesmo perfil de procedência dos escravos africanos foi encontrado para São José Del Rey pelos pesquisadores Afonso Graça Filho e Fabio Vieira Pinto, entre os anos de 1743 e 1850, por meio da consulta em inventários. Os escravos dessa região vinham em sua maioria da África Centro-Oeste, eram Benguelas, Ganguelas, Angolas, Cabindas, Cassanges, Rebolos e Congos, um total de 82,1\% dos cativos africanos; logo após vinham os da África Ocidental, 8,19\% (a maior parte de procedência Mina) seguidos pelos da África Oriental, que perfaziam $1,08 \%$ (Moçambiques). ${ }^{32}$

A dependência do trafico internacional de escravos também foi percebida por Marcos Andrade, em estudo sobre o Sul de Minas (Termos de Baependi e Campanha). Em cada uma dessas localidades a percentagem de africanos era superior a $45 \%$. De acordo com a análise empreendida pelo pesquisador, o Sul de Minas e a Província mineira seguiram a tendência do tráfico internacional, o que levou a um grande contingente de cativos provenientes da África Central.

\footnotetext{
31 PINHEIRO, Fabio Wilson Amaral. Op. cit., p. 54-55.

32 GRAÇA FILHO, Afonso de Alencastro \& PINTO, Fábio Carlos Vieira. Tráfico e famílias escravas em Minas Gerais. In: GONÇALVES, Andréa Lisly \& ARAUJO, Valdei Lopes de. Estado, região e sociedade: contribuições sobre história social e política. Belo Horizonte: Argvmentvm, 2008, p. 67.
} 
A grande maioria dos que vieram para Minas Gerais, na primeira metade do século XIX, era proveniente da África Central. Em todas as freguesias, o percentual de cativos desta área, quase sempre ficou acima de 90\%, com predominância para os angola, os banguela e os benguela. Em segundo lugar, estavam os cativos oriundos da África Ocidental, qualificados genericamente como "mina". Percebe-se que o percentual oscilava entre 6 e $11 \%$ e, a considerar as informações encontradas nos registros paroquiais, a entrada de cativos da África Ocidental nas freguesia do sul de Minas foi maior na década de $1780 .{ }^{33}$

De acordo com o historiador Robert Slenes, em seus estudos sobre o Sudeste brasileiro, as evidências apontam para uma supremacia nas senzalas desta região de escravizados provenientes da África Central Ocidental, portadores de uma homogeneidade cultural:

Nas fazendas do Rio e de São Paulo [e provavelmente nas mineiras fronteiriças aos vale do Paraíba fluminense e paulista], formadas em boa parte em regiões praticamente desabitadas a partir do final do século XVIII, quando não depois de 1820, os africanos constituíam a grande maioria dos escravos adultos antes do fim do tráfico. Além disso, eles provinham principalmente da África Central ocidental, o que significa que compartilhavam uma herança cultural e um patrimônio lingüístico bantu. (...) Finalmente, a grande maioria de crioulos adultos nas fazendas eram filhos de centro-africanos (...). ${ }^{34}$

No concernente à procedência dos escravos daquela posse de cativos (1837), encontramos na faixa referente às crianças quatro cativos de Cabinda; três cativos do Congo; três de Benguela, dois Cassange; um Monjolo; um Rebolo; 18 deles não tiveram essa variável mencionada. Entre os por nós designados como jovens/adultos (15 - 40 anos) existiram 28 Congos; 24 Cabinda; 10 Benguela; 06 Monjolo; 06 Cassange; 03 Rebolo; 02 Angola; um Mina; um Carioca e 34 não consta. Ou seja, na faixa onde se localizavam os escravos mais aptos para o trabalho - "jovens/adultos" - havia 58 cativos do Congo Norte, 21 de Angola e um Mina. O grupo dos idosos era composto por um Congo e três Benguela, para três deles não estava registrada tal informação. Dentre os recém nascidos não havia menção à procedência, e entre os cativos onde não foi possível se saber a idade encontramos dois do Congo, um de Benguela, três de Cabinda e um Rebolo, um Muange, e para seis não consta a procedência.

Analisando outra das duas famílias, notamos que o Comendador Francisco de Paula Lima, patriarca da família Paula Lima, falecido no dia 26 de novembro de 1865, possuiu uma propriedade majoritariamente masculina, onde os homens somavam $68,1 \%$ da posse e as

\footnotetext{
33 ANDRADE, Marcos Ferreira de. Elites regionais e a formação do Estado imperial brasileiro - Minas Gerais - Campanha da Princesa (1799-1850). Rio de Janeiro: Arquivo Nacional, 2008, p. 286.

34 SLENES, Robert. A Árvore de Nsanda transplantada: cultos kongo de aflição e identidade escrava no Sudeste brasileiro (século XIX). In: LIBBY, Douglas Cole \& FURTADO, Júnia Ferreira (Orgs.). Trabalho livre, trabalho escravo: Brasil e Europa, séculos XVII e XIX. São Paulo: Annablume, 2006, p. 279.
} 
mulheres 31,4\% (Tabela VI). Para um indivíduo, 0,5\%, não foi possível conhecer o sexo. Nesta posse também houve uma maior concentração de cativos entre os jovens/adultos (15-40 anos), com 136 escravos. Logo depois, 35 idosos, seguidos por 29 crianças e apenas 01 recémnascido, um pequeno número se comparado à escravaria de Dona Anna Maria do Sacramento. Os escravos descritos como crioulos eram 19, dois deles procedentes da Bahia.

Tabela VI

Sexo e faixa etária dos cativos do Comendador Francisco de Paula Lima, 1866

\begin{tabular}{ccccccccccc}
\hline $\begin{array}{c}\text { Faixa etária } \\
\text { Sexo }\end{array}$ & $\begin{array}{c}\text { Recém } \\
\text { nascido }\end{array}$ & $\mathbf{\%}$ & $\begin{array}{c}\mathbf{1 - 1 4} \\
\text { (crianças) }\end{array}$ & $\mathbf{\%}$ & $\begin{array}{c}\mathbf{1 5 - 4 0} \\
\text { (jovens/adultos) }\end{array}$ & $\mathbf{\%}$ & $\begin{array}{c}\mathbf{4 1 +} \\
\text { (idosos) }\end{array}$ & $\mathbf{\%}$ & Total & $\mathbf{\%}$ \\
\hline Masculino & - & - & 21 & 65,6 & 89 & 65,4 & 29 & 82,9 & 139 & 68,1 \\
Feminino & 01 & 100 & 11 & 34,4 & 47 & 34,6 & 05 & 14,2 & 64 & 31,4 \\
Não consta & - & - & - & - & - & - & 01 & 2,9 & 01 & 0,5 \\
Total & $\mathbf{0 1}$ & $\mathbf{1 0 0}$ & $\mathbf{3 2}$ & $\mathbf{1 0 0}$ & $\mathbf{1 3 6}$ & $\mathbf{1 0 0}$ & $\mathbf{3 5}$ & $\mathbf{1 0 0}$ & $\mathbf{2 0 4}$ & $\mathbf{1 0 0}$ \\
\hline
\end{tabular}

Fonte: Inventário post-morten do Comendador Francisco de Paula Lima, 1866. Arquivo Histórico da Universidade Federal de Juiz de Fora (doravante AHUFJF). Cartório do 1 Ofício Cível.

Por meio do conhecimento do sexo e da faixa etária de seus cativos podemos perceber que os crioulos estiveram em sua maioria na faixa etária das crianças, num total de 15 , correspondendo 46,9\% das crianças. Três pertenciam à faixa etária de 15-40 anos, inclusive os dois descritos como "da Bahia", 2,2\%. O outro crioulo era a recém-nascida Rozaria, de oito meses, filha de Theophila. Os oito africanos conhecidos dividem-se entre a terceira e a quarta faixa etária, respectivamente, seis, 4,4\%, (dois Congos, dois Rebolos, um Cabinda e o outro Cabo Verde) e dois, 5,7\%, (Moçambique e Benguela). Entretanto, a imensa maioria dos cativos onde não foi possível se saber sua origem pertencia à faixa dos jovens, totalizando 127 escravos (93,4\%), em seguida, computamos 35 na faixa acima dos 41 anos $(94,3 \%)$, e por fim 17 escravos, 51,7\%, compunham a faixa etária concernente às crianças.

No ano de 1877, aos 27 dias do mês de outubro, faleceu a viúva do Comendador Francisco de Paula Lima, Dona Francisca Benedicta de Miranda Lima. De acordo com o inventário da mesma, esta senhora possuía à época 130 cativos, o documento listou ainda, nove ingênuos. Passados onze anos, desde o inventário do Comendador, percebemos um decréscimo no número de escravos, o que não é de se espantar se consideramos que neste intervalo de tempo houve a partilha dos bens daquele senhor, inclusive os escravos, no ano de 1866. Logicamente podem ter existido outros fatores que levaram a essa baixa no número de cativos, como vendas, óbitos e dívidas. 
Ainda podemos encontrar mais homens do que mulheres escravas, todavia, apesar da diferença, os números tendem mais a se equilibrar. Houve uma diminuição no número total de homens com relação às mulheres. Enquanto estes diminuem, mais ou menos em torno de $10 \%$, estas aumentam na mesma proporção.

A posse dos Paula Lima possuiu tanto no inventário do Comendador Francisco de Paula Lima, quanto no de sua esposa, D. Francisca Benedicta de Miranda Lima, um pequeno percentual de africanos com procedência conhecida (Tabela VII). Essas procedências aproximam-se às da escravaria de D. Anna Maria do Sacramento, primeira esposa do capitão Antonio Dias Tostes. Lá havia também, dentre os africanos com procedência conhecida, uma maioria proveniente da "África Central ou Centro-Oeste Africano". Em 1866, oito cativos eram da "África Central", temos dois Congos e um Cabinda; de "Angola" dois Rebolos e um Benguela; encontramos da “África Oriental” um Moçambique e da “África Ocidental” um Cabo Verde. Já em 1877 da “África Central ou Centro-Oeste Africano” foram três Congos e três Cabindas; de "Angola", dois Rebolo, um Benguela, um Angola e um Cassange; da "África Oriental” temos dois escravos de Moçambique da “África Ocidental” havia um Cabo Verde. ${ }^{35}$

Tabela VII

Procedência dos cativos africanos da família Paula Lima, Juiz de Fora 1866 e 1877

\begin{tabular}{cccc}
\hline $\begin{array}{c}\text { Ano do inventário } \\
\text { Procedência }\end{array}$ & $\mathbf{1 8 6 6}$ & $\mathbf{1 8 7 7}$ & Total \\
\hline Congo & 02 & 01 & 03 \\
Cabinda & 01 & 02 & 03 \\
Rebolo & 02 & - & 02 \\
Cassange & - & 01 & 01 \\
Benguela & 01 & - & 01 \\
Angola & - & 01 & 01 \\
Moçambique & 01 & 01 & 02 \\
Cabo Verde & 01 & - & 01 \\
Total & $\mathbf{0 8}$ & $\mathbf{0 6}$ & $\mathbf{1 4}$ \\
\hline
\end{tabular}

Fonte: Inventário post-morten do Comendador Francisco de Paula Lima, 1866 e inventário post-mortem de sua esposa Dona Francisca Benedicta de Miranda Lima, 1877. AHUFJF. Cartório do 1o Ofício Cível

Coincidência? Talvez não. Duas hipóteses podem ser possíveis para se pensar esta semelhança. Primeiro, como o número de procedências dadas a conhecer é pequeno, nossa análise pode estar enviesada distorcendo o que realmente aconteceu. Uma segunda hipótese a ser pensada é a de que, até o fim efetivo do tráfico os traficantes e compradores de cativos

${ }^{35}$ Cf. KARASCH, op. cit., 2000. 
tenham continuado a ter preferência na compra de cativos provenientes das regiões acima citadas, ou que mesmo após a extinção do tráfico, com o consequente redirecionamento desta prática, tenham continuado essa dinâmica só que agora se valendo da compra destes Congos, Cabindas, Rebolos, etc. no mercado interno.

Como bem afirmou José Roberto Góes, ninguém pode negar que a imigração forçada africana para o Brasil foi marcante na nossa formação e conformou muitas das nossas características. $\mathrm{O}$ autor argumentou que o estudo da escravidão não pode perder de vista tal aspecto, pois esse grande contingente populacional escravo proveniente do tráfico internacional nos deu "a sua cor". ${ }^{36}$ Para Góes:

\footnotetext{
Em outras palavras, o ser escravo africano no Brasil deve ter importado na vivência de situações radicalmente (e dolorosamente) particulares por parte dos cativos. Este é um dado elementar sem cuja adequada consideração a compreensão de aspectos essenciais da escravidão estará comprometida. As alternativas que o cativeiro propunha a esses escravos bem como as soluções que puderam encontrar estiveram visceralmente marcadas por sua condição de cativos estrangeiros. ${ }^{37}$
}

A herança africana sem dúvida fez parte da experiência que os cativos tiveram em sua condição escrava. Portanto, seja no interior das fazendas e sítios, na área rural ou urbana, no nordeste ou no sudeste brasileiro, os traços da herança africana, constantemente renovados pelo tráfico se fizeram sentir cotidianamente entre os escravos. Isto ocorreu por meio do casamento, das práticas de nomeação dos filhos, do apadrinhamento de seus filhos, em sua religiosidade, nas lutas contra a opressão senhorial e em tantas outras atitudes tomadas por eles na busca pela conquista de um espaço de autonomia, mesmo que restrito, dentro do sistema escravista.

\section{BIBLIOGRAFIA:}

1. ANDRADE, Marcos Ferreira de. Elites regionais e a formação do Estado imperial brasileiro Minas Gerais - Campanha da Princesa (1799-1850). Rio de Janeiro: Arquivo Nacional, 2008.

2. ANDRADE, Rômulo Garcia de. Limites impostos pela escravidão a comunidade escrava e seus vínculos de parentesco: Zona da Mata de Minas Gerais, século XIX. 2v. São Paulo: USP, 1995. (Tese de Doutoramento).

\footnotetext{
${ }^{36}$ GÓES, José Roberto. O cativeiro imperfeito: um estudo sobre a escravidão no Rio de Janeiro na primeira metade do século XIX. Vitória: Lineart, 1993, p. 34.

${ }^{37}$ Ibidem, p. 34. José Roberto Góes, utilizando-se de viajantes, oferece ao longo do livro uma "visão" acerca da "enxurrada" de cativos que chegavam ao Rio de Janeiro da primeira metade do XIX.
} 
3. CARrARA, Angelo Alves. A Zona da Mata de Minas Gerais: diversidade econômica e continuísmo (1839-1909). Niterói, RJ: Universidade Federal Fluminense, 1993. (Dissertação de Mestrado em História).

4. ELTIS, David. The volume and structure of the transatlantic slave trade: a reassessment. William and Mary Quaterly, 3d Series, Volume 58, Number I, January 2001.

5. FLORENTINO, Manolo. Em costas negras: uma história do tráfico de escravos entre a África e o Rio de Janeiro, século XVIII e XIX. São Paulo: Companhia das Letras, 1997.

6. FRAGOSO, João Luis \& FERREIRA, Roberto Guedes. Alegrias e Artimanhas de uma fonte seriada, despacho de escravos e passaportes da Intendência de Polícia da Corte, 1819-1833. Seminário de História Quantitativa e serial no Brasil: um balanço. Ouro Preto, MG: ANPUH-MG, 2001.

7. GRAÇA FILHO, Afonso de Alencastro \& PINTO, Fábio Carlos Vieira. Tráfico e famílias escravas em Minas Gerais. In: GONÇALVES, Andréa Lisly \& ARAUJO, Valdei Lopes de. Estado, região e sociedade: contribuições sobre história social e política. Belo Horizonte: Argvmentvm, 2008.

8. GRAHAM, Sandra Lauderdale. Caetana diz não: histórias de mulheres da sociedade escravista brasileira. São Paulo: Companhia das Letras, 2005.

9. GUIMARÃES, Elione Silva. Múltiplos viveres de afrodescendentes na escravidão e no pósemancipação: família, trabalho, terra e conflito (Juiz de Fora - MG, 1828-1928). São Paulo: Annablume; Juiz de Fora: Funalfa Edições, 2006.

10. KARASCH, Mary C. A vida dos escravos no Rio de Janeiro (1808-1850). São Paulo: Companhia das Letras, 2000.

11. KLEIN, Herbert S. "A demografia do tráfico atlântico de escravos para o Brasil." Estudos Econômicos, São Paulo, v.17, n. 2, pág. 129-149, maio/ago. 1987.

12. . Escravidão africana: América Latina e Caribe. São Paulo: Brasiliense, 1987.

13. LACERDA, Antonio Henrique Duarte. Os padrões de alforrias em um município cafeeiro em expansão: Juiz de Fora, Zona da Mata de Minas Gerais, 1844-1888. São Paulo: Fapeb; Annablume, 2006.

14. MOTTA, José Flávio \& MARCONDES, Renato Leite. "O comércio de escravos no vale do Paraíba paulista: Guaratinguetá e Silveiras na década de 1870." Estudos Econômicos. São Paulo: IPE/USP, 30(2): pp.267-299, 2000.

15. PAIVA, Clotilde Andrade \& BOTELHO, Tarcísio Rodrigues. População e espaço no século XIX mineiro: algumas evidências de dinâmicas diferenciadas. In: Anais do VII Seminário Sobre a Economia Mineira. Belo Horizonte: CEDEPLAR/UFMG, 1995. 
16. PAIVA, Eduardo França. Escravidão e universo cultural na colônia: Minas Gerais, 17161789. Belo Horizonte: Editora da UFMG, 2001.

17. PINHEIRO, Fabio Wilson Amaral. O tráfico atlântico de escravos na formação dos plantéis mineiros, Zona da Mata (c.1809 - c.1830). Rio de Janeiro: Universidade Federal do Rio de Janeiro, 2007, p. 148-149. (Dissertação de Mestrado em História).

18. RODRIGUES, Jaime. O infame comércio: propostas e experiências no final do tráfico de africanos para o Brasil (1800-1850). Campinas: Editora da Unicamp/CECULT, 2000.

19. SLENES, Robert W. The Brazilian Internal Slave Trade, 1850-1888: Regional economies, slave experience and the politics of a peculiar market. In: Walter Johnson. (Org.). Domestic Passages: Internal Slave Trades in the Americas, 1808-1888. New Haven: Yale University Press, 2005.

20. The demography and economics of brazilian slavery: 1850-1888. Tese de Doutoramento. Stanford University, 1976.

21. _. Na senzala uma flor: esperanças e recordações na formação da família escrava -Brasil Sudeste, século XIX. Rio de Janeiro: Nova Fronteira, 1999.

22. A Árvore de Nsanda transplantada: cultos kongo de aflição e identidade escrava no Sudeste brasileiro (século XIX). In: LIBBY, Douglas Cole \& FURTADO, Júnia Ferreira (Orgs.). Trabalho livre, trabalho escravo: Brasil e Europa, séculos XVII e XIX. São Paulo: Annablume, 2006.

23. STEIN, Stanley. Grandeza e decadência do café no Vale do Paraíba, com referência especial ao município de Vassouras. São Paulo: Brasiliense, 1961. 